\title{
Repeated Acceleration Ability (RAA): A New Concept with Reference to Top-Level Field
}

\author{
and Assistant Soccer Referees
}

\author{
José Carlos Barberó-Álvarez ${ }^{1 A B C D E F G}$, PhD; Daniel Boullosa ${ }^{\text {2ADEG }}$, PhD; Fábio Yuzo Nakamura ${ }^{\text {ADDEG }}$, PhD; \\ Germán Andrín $^{4 \mathrm{BEG}}$, BPhEd; Matthew Weston ${ }^{\text {5CDEG }}$, PhD
}

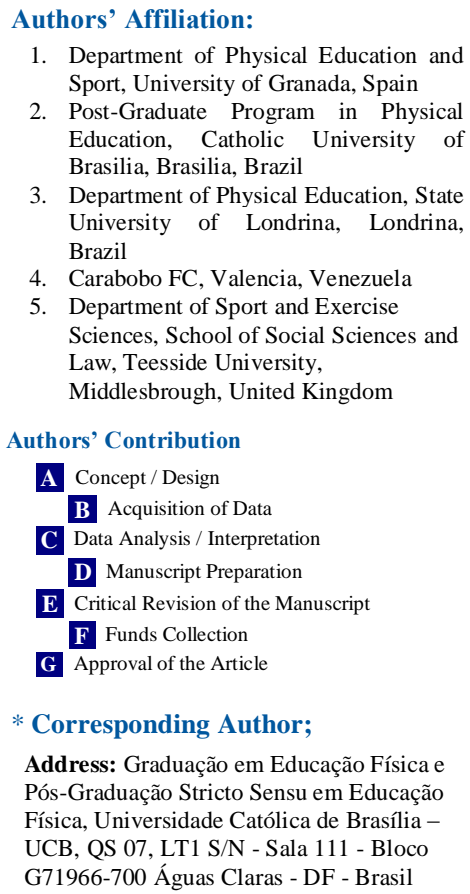

E-mail: d_boullosa@yahoo.es

Received: Mar 25, 2013

Accepted: Oct 22, 2013

Available Online: Nov 29, 2013

\begin{abstract}
Purpose: To perform an exploratory characterization of repeated sprint sequences (RSS) and repeated acceleration sequences (RAS) in top level soccer referees.

Methods: 7 field and 7 assistant referees were monitored during 2007 America's Soccer Cup with GPS technology. Sprints of $>18 \mathrm{~km} \cdot \mathrm{h}^{-1}$ and accelerations of $>1.5 \mathrm{~m} \cdot \mathrm{s}^{-2}$ were considered as high intensity activities. RSS and RAS were defined as a minimum of 3 consecutive bouts interspersed with a maximum of $45 \mathrm{~s}$.
\end{abstract}

Results: Field and assistant referees performed substantially more accelerations than sprints. Neither field nor assistant referees recorded any RSS. In contrast, total distance performing RAS amounted to $\sim 37 \%$ and $\sim 20 \%$ of the total distance covered by accelerations during the entire match for field and assistant referees, respectively. Only field referees exhibited fatigue-related reductions in RAS characteristics between halves.

Conclusion: The results of the present study would appear to support the appropriateness of a repeated acceleration ability (RAA) concept, instead of the repeated sprint ability (RSA) concept, in soccer referees. Further studies should assess RAS in referees and athletes of different team sports for designing better training exercises and physiological testing.

Key Words: Time Motion; Intermittent Sports; Global Positioning System; Performance; Fatigue

Asian Journal of Sports Medicine, Volume 5 (Number 1), March 2014, Pages: 63-66

\section{INTRODUCTION}

$\mathrm{R}$ epeated sprint ability (RSA), defined as the ability to perform short sprints $(<10 \mathrm{~s})$ interspersed with brief recovery periods $(<1 \mathrm{~min})$, has been proposed as one of the key fitness components in team sports ${ }^{[1]}$. Paradoxically, there are very few studies on the occurrence of repeated sprint sequences (RSS) during competitive matches in team sports ${ }^{[1]}$. Furthermore, Buchheit et al. ${ }^{[2]}$ have recently questioned the validity of RSA as they did not observe any RSS during an international tournament of young soccer players. In another recent study, Carling et al. ${ }^{[3]}$ reported that most high-intensity actions (i.e. sprints $>19.8 \mathrm{~km} \cdot \mathrm{h}^{-1}$ for a minimum of $1 \mathrm{~s}$ duration) during soccer official competitions in professional players were performed after recovery durations of $\geq 61 \mathrm{~s}$. Thus, the current competitive match analysis data raise some concerns on RSA construct validity for team sports. This would be applied also to field and assistant soccer referees as they experience a similar intermittent match work pattern to players ${ }^{[4]}$.

Recently, Osgnach et al. ${ }^{[5]}$ have pointed out the importance of accelerations for the quantification of high-intensity actions, as acceleration requires large amounts of metabolic power despite being performed at low velocities. In this regard, few studies have reported repeated acceleration sequences (RAS) in 
team sports. For instance, Aughey ${ }^{[6]}$ has reported that elite Australian football players nearly double the number of maximal accelerations in finals compared with regular season games, while the majority of accelerations occurred with less than $19 \mathrm{~s}$ of recovery. In another study ${ }^{[4]}$ with top-class soccer referees, there was described a reduction in accelerations in the second half with no observable decrements in highintensity and maximal-speed runs. From these previous reports, it would be hypothesized that the ability for performing repeated accelerations (i.e. repeated acceleration ability; RAA) in field and assistant referees would seem an important fitness component. This knowledge would be of interest for providing a more precise characterization of match activities, and therefore improving the application of high-intensity actions testing and training ${ }^{[3,7]}$.

Therefore, the current study aims to quantify the occurrences and characteristics of both RSS and RAS in a group of top class field and assistant referees during an international tournament. It was hypothesized that RAA could represent a better index of high intensity actions than RSA in this population due to the wider occurrences and changes when comparing fatigue-related characteristics between the first and second half of matches.

\section{METHODS AND SUBJECTS}

Seven top-level field referees (age: $40 \pm 2.2 \mathrm{yrs}$; height: $1.75 \pm 0.04 \mathrm{~m}$; weight: $68 \pm 6.8 \mathrm{~kg}$ ) and 7 assistants (age: $36 \pm 5.2$ yrs; height: $1.74 \pm 0.03 \mathrm{~m}$; weight: 76.1 $\pm 6.3 \mathrm{~kg}$ ) were monitored using a GPS device $(1 \mathrm{~Hz})$ equipped with a triaxial accelerometer $(100 \mathrm{~Hz})($ SPI Elite, GPSports Systems, Australia) during 2007 America's Soccer Cup as previously described ${ }^{[4]}$. Activities from every couple of officials were recorded during the same match with a total of 7 matches included in this study. Repeated high-intensity actions were defined as a minimum of 3 consecutive bouts (sprints $>18 \mathrm{~km} \cdot \mathrm{h}^{-1}$ or accelerations $>1.5 \mathrm{~m} \cdot \mathrm{s}^{-2}$ ) interspersed with a maximum of $45 \mathrm{~s}$. The total number of sprints and accelerations, and the distance covered per sequence were subsequently recorded for determination of RAS (i.e. 3 consecutive accelerations interspersed with a maximum of $45 \mathrm{~s}$ ), and RSS (i.e. 3 consecutive sprints interspersed with a maximum of 45 s).

\section{Statistical Analysis:}

Data are expressed as mean \pm standard deviation. Mean differences in the distance covered and the number of bouts between sprints and accelerations, along with between-half differences in activities were calculated. Uncertainty of the estimates is shown as 90\% confidence intervals. Effect sizes were also calculated using a custom-made spreadsheet ${ }^{[8]}$.

\section{RESULTS}

The distance covered and the number of bouts for sprints and accelerations are displayed in Table 1. Field and assistant referees performed substantially more accelerations than sprints. Peak velocities at the end of accelerations were $19.15 \pm 0.61$ and $16.55 \pm 1.85 \mathrm{~km} \cdot \mathrm{h}^{-1}$ for field and assistant referees, respectively.

Table 1: Total match distance covered and the number of bouts during high-intensity running and accelerations for field referees and assistant referees

\begin{tabular}{llcccc} 
Variable & & $\begin{array}{c}\text { Accelerations } \\
\text { Mean (SD) }\end{array}$ & $\begin{array}{c}\text { Sprints } \\
\text { Mean (SD) }\end{array}$ & $\begin{array}{c}\text { Mean difference } \\
\text { (90\% CI) }\end{array}$ & $\begin{array}{c}\text { Effect Size } \\
\text { (90\% CI) }\end{array}$ \\
\hline \multirow{2}{*}{ Field Referees } & Distance (m) & $1539(115)$ & $698(288)$ & $841(632$ to 1050$)$ & $3.84(2.15$ to 4.98$)$ \\
Assistant Referees & Number (no.) & $73(28)$ & $38(17)$ & $35(13$ to 57$)$ & $1.51(0.42$ to 2.39) \\
& Distance (m) & $716(54)$ & $90(93)$ & $626(554$ to 698$)$ & $8.23(5.12$ to 10.19$)$ \\
& Number (no.) & $56(10)$ & $8(7)$ & $48(40$ to 56) & $5.56(3.34$ to 7.00$)$
\end{tabular}

SD: Standard Deviation; CI: Confidence Interval 
Table 2: Repeated acceleration sequences (RAS) profile performed by field and assistant referees during the first and second half, and during the whole match

\begin{tabular}{|c|c|c|c|c|c|}
\hline Variable & $\begin{array}{c}\text { Match } \\
\text { Mean (SD) }\end{array}$ & $\begin{array}{c}\text { First Half } \\
\text { Mean (SD) }\end{array}$ & $\begin{array}{l}\text { Second Half } \\
\text { Mean (SD) }\end{array}$ & $\begin{array}{c}\text { Mean difference } \\
(90 \% \mathrm{CI})\end{array}$ & $\begin{array}{l}\text { Effect Size } \\
(90 \% \mathrm{CI})\end{array}$ \\
\hline \multicolumn{6}{|l|}{ Field Referees } \\
\hline Total RAS distance $(\mathrm{m})$ & $570(470)$ & $396(241)$ & $174(242)$ & $-222(-452$ to 8$)$ & $-0.92(-1.77$ to 0.06$)$ \\
\hline Total distance covered per RAS (m) & $81(37)$ & $84(37)$ & $76(38)$ & $-8.0(-43.7$ to 27.7$)$ & $-0.21(-1.08$ to 0.68$)$ \\
\hline Mean distance of accelerations (m) & $20.2(9.0)$ & $20.2(6.6)$ & $20.3(4.7)$ & $0.1(-5.4$ to 5.6$)$ & $0.02(-0.86$ to 0.90$)$ \\
\hline Recovery time between accelerations (s) & $20.8(7.4)$ & $21.1(6.9)$ & $20.1(8.6)$ & $-1.0(-8.4$ to 6.4$)$ & $-0.13(-1.00$ to 0.76$)$ \\
\hline RAS (no.) & $7.0(3.9)$ & $4.7(1.6)$ & $2.3(2.4)$ & $-2.4(-4.3$ to -0.5$)$ & $-1.18(-2.04$ to -0.15$)$ \\
\hline Accelerations per RAS (no.) & $3.9(1.5)$ & $4.2(1.6)$ & $3.5(1.2)$ & $-0.7(-2.1$ to 0.7$)$ & $-0.49(-1.35$ to 0.43$)$ \\
\hline Mean duration of Accelerations (s) & $5.6(1.4)$ & $5.6(1.2)$ & $5.8(1.6)$ & $0.2(-1.2$ to 1.6$)$ & $0.14(-0.75$ to 1.01$)$ \\
\hline \multicolumn{6}{|l|}{ Assistant Referees } \\
\hline Total RAS distance (m) & $147(57)$ & $64(53)$ & $83(93)$ & $19(-53$ to 91$)$ & $0.25(-0.65$ to 1.12$)$ \\
\hline Total distance covered per RAS (m) & $47(18)$ & $41(17)$ & $53(19)$ & $12(5$ to 29$)$ & $0.67(-0.28$ to 1.52$)$ \\
\hline Mean distance of accelerations (m) & $13.9(5.1)$ & $12.2(3.7)$ & $15.6(5.8)$ & $3.4(-1.2$ to 8.0$)$ & $0.70(-0.25$ to 1.55$)$ \\
\hline Recovery time between accelerations (s) & $16.6(7.1)$ & $15.5(8.6)$ & $15.7(5.6)$ & $0.2(-6.7$ to 7.1$)$ & $0.03(-0.85$ to 0.90$)$ \\
\hline RAS (no.) & $3.1(1.2)$ & $1.6(1.5)$ & $1.5(0.7)$ & $-0.1(-1.2$ to 1.0$)$ & $-0.09(-0.96$ to 0.80$)$ \\
\hline Accelerations per RAS (no.) & $3.4(0.6)$ & $3.3(0.5)$ & $3.5(0.7)$ & $0.2(-0.38$ to 0.78$)$ & $0.33(-0.58$ to 1.19$)$ \\
\hline Mean duration of Accelerations (s) & $4.8(1.0)$ & $4.4(0.8)$ & $5.2(1.1)$ & $0.8(-0.1$ to 1.7$)$ & $0.83(-0.14$ to 1.69$)$ \\
\hline
\end{tabular}

Neither field nor assistant referees recorded any RSS. The data relating to RAS are presented in Table 2. Total distance performing RAS amounted to $\sim 37 \%$ and $\sim 20 \%$ of the total distance covered by accelerations during the entire match for field and assistant referees, respectively. The field referees recorded moderate reductions in the second half for total RAS distance and the number of RAS bouts, with small reductions in the total distance covered per RAS and the number of accelerations per RAS. Conversely, the assistant referees recorded a moderate increase in total distance covered per RAS, mean distance of accelerations and mean duration of accelerations during the second half, with small increases for total RAS distance and the number of accelerations per RAS.

\section{DISCUSSION}

The aim of this study was to quantify the occurrences and characteristics of RSS and RAS performed by toplevel soccer referees and assistants. The main finding of this study was that both field and assistant referees exhibited RAS while this was not evident for RSS. This finding is in line with recent observations ${ }^{[2]}$ suggesting that RSA may not be a target capacity in match officials as the rate of occurrence of RSS during matches when assessed with classical velocity thresholds is far below the concept underlying RSA.

One interesting point refers to RSA testing design as the work-to-rest ratio of typical RSA tests does not fit the one reported during soccer matches $\left.{ }^{[2,} 3\right]$. In contrast, the work-to-rest ratio observed in the current study would confirm the validity of the RAA concept in referees. Therefore, RAA and not RSA could be a more specific ability in field and assistant referees as inferred from our observations. These findings also generate some concerns on the appropriateness of RSA evaluation in officials. Further longitudinal studies should be conducted for evaluating RAA in greater samples for confirming the current findings.

From our observations, it appears that referees experience some fatigue-related decrement in RAA while comparing the first and second halves. This measure is probably more sensitive than quantifying sprints or high-intensity runs to track running-related fatigue ${ }^{[4,9]}$. However, assistants are less prone to experiencing reduction in RAA confirming their lower physical demand compared to field referees ${ }^{[4,9]}$.

While this is a preliminary study, some potential limitations should be highlighted for better designing of further investigations. Firstly, the low number of 
officials and matches recorded would suggest some caution for generalization of our results. Secondly, the reliability and validity of GPS units for detecting accelerations is still under debate ${ }^{[10]}$ thus suggesting some caution with our data with further studies needed. Nevertheless, the thresholds selected for recording accelerations and velocities in the current study would be less problematic than in other studies with elite athletes.

\section{CONCLUSION}

Both field and assistant referees did not exhibit any RSS while RAS amounted to $\sim 37 \%$ and $\sim 20 \%$ of the total distance covered by accelerations during the entire match for field and assistant referees, respectively. From the current results, the revision of the RSA concept in referees and team sport athletes may be suggested. Thus, the evaluation of RAA would be more appropriate for designing better training exercises and physiological testing in soccer referees and other team sport athletes. Further studies with greater samples are needed for confirming our results in this and other populations.

\section{ACKNOWLEDGMENTS}

The authors would like to thank referees for participation on this study.

Conflict of interests: None

\section{REFERENCES}

[1] Girard O, Mendez-Villanueva A, Bishop D. Repeated-sprint ability - part I: factors contributing to fatigue. Sports Med 2011;41:67394.

[2] Buchheit M, Mendez-Villanueva A, Simpson BM, et al. Repeated-sprint sequences during youth soccer matches. Int J Sports Med 2010;31:709-16.

[3] Carling C, Le Gall F, Dupont G. Analysis of repeated high-intensity running performance in professional soccer. J Sports Sci 2012;30 :325-36.

[4] Barbero-Álvarez J, Boullosa DA, Nakamura FY, et al. Physical and physiological demands of field and assistant soccer referees during America s Cup. J Strength Cond Res 2012;26:1383-8.

[5] Osgnach C, Poser S, Bernardini R, et al. Energy cost and metabolic power in elite soccer: a new match analysis approach. Med Sci Sports Exerc 2010; 42:170-8.

[6] Aughey RJ. Increased High-Intensity Activity in Elite Australian Football Final Matches. Int J Sports Physiol Perform 2011;6:367-79.

[7] Dawson B. Repeated-sprint ability: where are we? Int J Sports Physiol Perform 2012;7:285-9.

[8] Hopkins WG. Spreadsheets for analysis of controlled trials, with adjustment for a subject characteristic. Sportscience 2006;10:46-50.

[9] Krustrup P, Helsen W, Randers MB, et al. Activity profile and physical demands of football referees and assistant referees in international games. J Sports Sci 2009;27:1167-76.

[10] Buchheit M, Al Haddad H, Simpson BM, et al. Monitoring accelerations with GPS in football: time to slow down? Int J Sports Physiol Perform In press. 